\title{
COMPUTADOR PARA INTERAÇÃO COMUNICATIVA
}

\section{Comunicação assistida pelo computador pressupõe prática pedagógica que valorize a cultura e a cidadania}

Na comunicação está uma das chaves para a reestruturação da educação. Há que se refletir e se trabalhar a comunicação para que se proceda a transformação da natureza da escola, para que ela se torne mais crítica frente às transformações sociais. Essa comunicação social ou escolar tem que estar comprometida com a realização de um ser cidadão, corpo, espírito e mente em transformação, para que continue a aprender por toda a vida. Um cidadão que se comprometa tanto com a aprendizagem quanto com o trabalho colaborativo, e que contribua para melhorar a vida individual e coletiva em seu país.

Caracterizo como comunicação escolar a comunicação que se mobiliza no processo de relações entre pessoas concretas, na escola, com uma história vivida no mundo. Evidentemente, inclui também as diversas mídias presentes (ou não) na escola. Essa comunicação se articula à cultura na qual está inserida. Ela é limitada no tempo e no espaço da realidade escolar, mas não pode se desvincular do conjunto da sociedade. Refiro-me, em particular, à comunicação escolar, aquela cujas interações se desenvolvem no ambiente escolarentre diretores, coordenadores, professores, alunos e pais de alunos como parte de uma comunicação mais ampla, a social. Essa comunicação é marcada ainda pela cultura presente na sala de aula ou pelas culturas, uma vez que podemos ter professores e alunos oriundos de culturas diferentes, situação muito comum nas escolas.

Assim como as linhas que norteiam a produção da comunicação social vêm aperfeiçoando-se, transformando-se a partir das incorporações críticas, as linhas norteadoras da realização da comunicação escolar também deveriam se aperfeiçoar. Essa evolução, no entanto, vem sendo mais lenta. A relação entre comunicação e educação, incluindo a comunicação escolar e as mídias, merece elaboração mais aprofundada e compromissada com a melhoria da qualidade de vida na sociedade.

Emprega-se o termo mídia ao se referir aos meios de comunicação, cujas características fortes são a comutação e a mutabilidade. Em seu livro A cultura das mídias, Santaella posiciona-se: “A opção pela palavra mídias no plural, empregada neste livro, não foi casual, mas deliberada. $\mathrm{O}$ que se pretende pôr em relevo são justamente os traços diferenciais e sui generis, quase idiossincráticos, de cada mídia individual, para caracterizar a cultura que nasce nos trânsitos, intercâmbios, fricções e misturas entre os diferentes meios de comunicação"! .

\section{A AUTORA}

Iolanda Bueno de Camargo Cortelazzo Pesquisadora do Centro de Tecnologia Intemet da Universidade Santa Cecilia, Santos, Resquisadora da Escola do Futuro, da USP, Professora na Universidade Bandeirante, Săo Paulo, 
Cada mídia tem uma especificidade própria e não há uma substituição de uma pela outra, mas uma integração, em que cada uma pode ser mobilizada por seus usuários no cumprimento de sua função em suas articulações e redimensionamentos. Muitas mídias são negligenciadas na comunicação escolar. $\mathrm{O}$ mesmo aluno que se encontra na sala de aula como leitor de livro, copiador das mensagens do quadro de giz, ouvinte do professor, é - em sua casa, no bar da esquina, no clube - telespectador, radiouvinte, leitor de jornal e revista, usuário de computador e de Internet, jogador de video game.

Os meios de recuperação de informação não substituem os livros, ao contrário permitem que conteúdos de excelentes bibliotecas através de seus livros, discos, revistas - sejam distribuídos para que uma educação superlativa aconteça e o professor possa ficar liberado para se concentrar em aspectos mais criativos e humanos do ensino da produção da educação e comunicação escolares.

Quando o professor se apropria dos discursos das diferentes mídias e os trabalha comunicacionalmente em sua prática pedagógica, possibilita uma rede, uma teia entre e sobre o mundo real e a escola. Dessa forma, a comunicação escolar entre alunos e professores, levando em conta o conhecimento do mundo e a diversidade cultural, dinamiza-se e a educação se enriquece, tornando-se fator determinante para uma mudança educacional mais efetiva e eficaz.

Em outras palavras, trabalhar comunicacionalmente com grupos ou redes de mídias nas aulas e cursos escolares requer o desenvolvimento contínuo interativo de textos culturais significativos entre professores e alunos, com a intencionalidade de aperfeiçoar suas compreeensões sobre o mundo natural e cultural em que vivem. Tal trabalho comunicacional, semiótico-textual ${ }^{2}$, envolve interações cumulativas de professores e alunos com dados e informações sobre o mundo e a história de sua natureza, de sua cultura, posicionando-se e expressando-se, de modo significativo, com os elementos observados, elaborados e tornados melhor conhecidos, melhor sabidos.

Se, além da semiótica-textual, essa comunicação escolar considerar o agenda setting ${ }^{3}$, ou seja, como a mídia agenda as demandas da comunidade, e aí introduzir elementos que valorizem aspectos culturais, históricos, sociais e educacionais, elevando a condição de cidadão em direção a uma humanização mais profunda, a comunicação social estará sendo ampliada e enriquecida.

Refiro-me aqui a uma comunicação escolar que vem deixando de ser veiculada apenas pelas tradicionais tecnologias da lousa, giz e livros. Cada vez mais a comunicação escolar passa a ser otimizada pela introdução de outras tecnologias de comunicação social, tais como jornal, vídeo, videogravadora, máquina fotográfica, computador, modem. Elas aparecem nas práticas educacionais em sala de aula ou na tarefa escolar a ser feita em casa. Os professores sentem cada vez mais a necessidade de trazer, para a sua prática pedagógica, as mídias eletrônicas, no sentido de mediar a sua atuação e a construção conjunta do conhecimento com seus alunos.

2. Ver sobre o tema: Wolf, Mauro. Teorias da comunicação. 2. ed. Lisboa: Presença, 1992. (N.Ed.)

3. Ver sobre o tema. BARROS FILHO, Clóvis. Agenda setting e educação. Comunicação \& Educação. São Paulo: CCA-ECAUSP/Moderna, n. 5, jan./abr. 1996. p. 27-33. (N. Ed.) 
Uma vez superado o paradigma tradicional da comunicação/educação hipodérmica ${ }^{4}$ de transmissão de conhecimento unilateral - de um professor/emissor que sabe tudo para um aluno/receptor de cabeça vazia -, o professor conscientiza-se da necessidade de usar as tecnologias de comunicação de forma integrada e como meio para uma interação contínua e construtora, junto com seus alunos. Cada mídia desempenhando aquela função que lhe é exclusiva em rede com as demais, descortinando para alunos e professores um novo mundo de descobertas e construções significativas. Conforme McCarthy ${ }^{5}$, o professor exerce um papel de orientador das ações do aluno. Ele faz descobertas no mundo que o cerca, levantando questões que deverão ser trazidas à sala de aula para discussão conjunta, à luz do pensamento reflexivo, para chegarem às formulações que expliquem $\mathrm{e}$ teorizem aquelas descobertas. Professores e alunos transformam-se em coadjuvantes nessa exploração e reflexão conjunta.

\section{PROFESSOR COMO ORIENTADOR}

Uma vez que o professor, exercendo o papel de orientador, estimula e traz para a comunicação escolar as mídias já familiares aos alunos, mostra-lhes que a escola não está dissociada da vida real. O professor, que também é um cidadão e vive o seu cotidiano em um mundo real, estimula a ação e a reflexão de seus alunos, respeitando o desenvolvi- mento individual de cada um, fazendo-o crescer como ser humano e como cidadão, criando seus próprios valores, ideais e ideologia. Novamente, as mídias são fundamentais nesse processo. A orientação do professor para uma recepção ativa e crítica das mídias será facilitada se essas mídias estiverem integradas à ação pedagógica corrente na sala de aula.

Tomo, neste artigo, como mídia específica o computador e as redes de computadores, refletindo como essa mídia vem sendo utilizada na prática escolar.

De acordo com Blackwell ${ }^{6}$, tem-se, na escola, a instrução assistida pelo computador (CAI - Computer Assisted Instruction) e o desempenho assistido pelo computador (CAP - Computer Assisted Performance). Na instrução assistida pelo computador (CAI), o aluno é passivo, necessita-se pouca preparação do professor e o computador é o tutor. Já no desempenho assistido pelo computador (CAP), o aluno é ativo, necessita-se de muita preparação do professor e o computador é uma ferramenta.

A partir de minha experiência, acrescento a esses dois tipos um terceiro: a comunicação assistida pelo computador (CAC). Nesse caso, a atuação do aluno é tão ativa quanto a do professor; e o professor precisa estar muito bem preparado, tanto como especialista do conteúdo quanto como conhecedor da pedagogia e da didática específica de sua área, e ainda em relação à proficiência no uso operacional do computador, que é, então, um meio de comunicação (Quadro 1).

\footnotetext{
4. O termo hipodérmica aqui utilizado remete à corrente teórica que estudou a comunicação no início dos anos 30 , nos EUA, e que tem como principais pressupostos a linearidade da comunicação entre Emissor e Receptor, buscando sempre uma resposta ao estímulo transmitido pelo meio de comunicação. Tem forte influência da Psicologia behaviorista. Ver mais sobre o assunto em MATTELART, Armand e Michèle. Histórias das Teorias de Comunicação. São Paulo: Loyola. 1999. (N.Ed.)

5. McCARTHY, Bernice. The 4MAT system: teaching and learning styles with left/right mode techniques. (O sistema 4MAT: ensinando e aprendendo técnicas no modo certo/errado.) Excel, 1987.

6. BLACKWELL. Les. Rethiking the roles of technology in education. Proceedings of the Tenth Internacional Conference of Technology and Education. (Repensando o papel da tecnologia na educação. Atas da X Conferência Internacional de Tecnologia e Educação.) 1993. p. 691.
} 


\begin{tabular}{|c|c|c|c|}
\hline \multicolumn{4}{|c|}{ Quadro 1} \\
\hline & CAI & CAP & CAC \\
\hline aluno & passivo & ativo & ativo \\
\hline professor & pouca preparação & muita preparação & muita preparação \\
\hline computador & tutor & ferramenta & mídia \\
\hline
\end{tabular}

Elaborado a partir de Blackwell, 1993: 691.

Ainda segundo Blackwell, os programas de computador podem ser classificados em:

Software de informação: Programas que apenas transmitem informação sobre determinado tema. Exemplo na área de línguas: Verbals, Enciclopédia Grollier etc. (os exemplos são tirados de minha experiência).

Software tutorial: Programas que ensinam procedimentos para se realizar alguma tarefa ou trabalhar com algum programa de computador. Exemplo: introdução ao micro (Senac), Info 2000 (Prodam).

Software de exercício e prática: Programas que trabalham exercícios de instrução programada ou exercícios para o desenvolvimento de habilidades específicas, através de repetição, associação simples, múltipla escolha etc. Exemplos: Eclipse, Hangman, muitos dos softwares educativos disponíveis no mercado.

Esses tipos caracterizam mais a instrução assistida pelo computador (CAI). O professor só supervisiona, os alunos são passivos e o computador dirige a instrução.

Os próximos já se encaminham para o desempenho assistido pelo computador (CAP). Os alunos começam a ter um certo nível de interatividade e participação. A construção conjunta é cada vez mais possível. Exige-se uma preparação do professor ascendente, para que ele use essa ferramenta cada vez mais presente no ambiente escolar.

Jogos educacionais: Programas de jogos que envolvem conteúdos pedagógicos. Exemplos: Carmen San Diego in the World,
Jasão e o Velocínio de Ouro etc.

Simulação: Programas que apresentam situações semelhantes à vida real e os alunos podem participar e decidir. Exemplos: a série SIM (Simcity, Simlife, SimAnt, SimSpace), Dig It etc.

Solução de problemas: Programas que propõem problemas para serem solucionados pelos alunos. Não há uma resposta correta. $\mathrm{O}$ aluno descobre um processo para encontrar a solução. Exemplos: Decisions, Decisions.

Utilitários simples: Programas que executam tarefas simples e se limitam a fazer o que foi destinado para fazer. Exemplo: Programa para folha de pagamento, Controle de estoque, Grade de notas etc.

Software de autoria I: Programas que codificam o que o usuário quer realizar. O usuário não precisa conhecer linguagem de programação, pode criar outros programas seguindo fórmulas e receitas. Exemplo: Hyperstudio, Authorware. Everest etc.

Software de autoria II: Programas como os anteriores. A diferença é que é preciso conhecer a linguagem de programação usada pelo programa de computador. Exemplo: Linkway, Toolbook etc.

Linguagem de computador: Programas cuja linguagem o usuário tem que conhecer e tem que saber programar. Exemplo: Clipper, $\mathrm{C}++$, Visual basic, Delphi.

Aplicativos: Programas que realizam uma tarefa determinada, mas que não são limitados a uma operação. Exemplos: processador de texto, planilha eletrônica, banco de dados. 
Utilitário complexo: Programas que executam tarefas complexas para o usuário. Exemplos: editoração eletrônica (Page Maker, Photoshop etc.), CAD/CAM, MIDI, ACCESS etc.

Se essas ferramentas forem usadas para os alunos se comunicarem no seu próprio ambiente ou através da rede de computadores, local ou a distância, deixam de ser simples ferramentas e passam a ser meios de comunicação. Toda vez que um processador de texto ou um programa de apresentação é utilizado para que o aluno se expressse, comunicando-se com o mundo que o rodeia, passamos a ter a comunicação assistida pelo computador (CAC). Professores e alunos são, além de criadores e construtores, comunicadores.

Outros programas (softwares) também são fundamentais para a comunicação via computador.

Software de comunicação: Programas que permitem a um computador conversar com outros computadores, através de protocolos próprios. Exemplo: Bitcom, Quicklink etc.

Software de correio eletrônico: Programas que permitem a troca de mensagens eletrônicas entre usuários conectados a uma rede de computadores. Ex. MS Mail, Eudora, Pegasus.

Navegadores na WWW: Programas que permitem a navegação hipertextual através dos sítios da WWW; apenas usando texto (em ASCII) tem-se o Lynx. Já usando interfaces gráficas, o primeiro foi o Cello, seguido pelo Mosaic, Netscape Navigator, Netscape Communicator, Microsoft Internet Explorer.

Afirmo que cada uma dessas classes de programas pode ser enquadrada tanto na instru- ção assistida pelo computador (CAI) quanto no desempenho assistido pelo computador (CAP) ou na comunicação assistida pelo computador (CAC). Sua inclusão nesta ou naquela categoria depende de como o programa é gerenciado pelo professor. Podemos ter um correio eletrônico usado como pura troca de correspondência, gerenciada por um sistema de correio eletrônico eficiente; quanto ter um software de informação orientado por um professor criativo, provocando a criação de trocas culturais significativas entre alunos de várias regiões do mundo. Assim, a atuação gerenciadora do professor é essencial para o aluno aprender a fa$z e r$ e a transferir a sua aprendizagem para outras situações, de modo que possa tomar decisões e resolver problemas quando necessário.

\section{EDUCAÇÃO PARA O COTIDIANO}

Por outro lado, as tecnologias de comunicação imprimem de alguma forma uma força educativa na vida cotidiana, em geral fora do ambiente formal escolar, e exercem um impacto até certo ponto significativo na sociedade?

\section{O gerenciamento executado pelo pro-} fessor é que despertará nos seus alunos a comunicação interativa significativa ou apenas a execução mecânica e automática de comandos, bem como uma leitura crítica das mídias que os tornará proficientes na decodificação de possíveis manipulações ideológicas, religiosas etc.

Por isso, ao colocar no início deste trabalho que a comunicação escolar deve estar sintonizada com a comunicação social,

7. GARZÓN, Artur. Contexto latinoamericano, tecnologia y educación. Tradición y pertinencia. Tecnologia y Comunicación Educativas. (Contexto latino-americano, tecnologia e educação. Tradição e pertinência. Tecnologia e Comunicação Educativas.) [s.l.]. ano 9, 22 enero-marzo, 1994, p. 51-64. 
lembro que a Comissão Internacional sobre a Educação para o Século XXI, da UNESCO, presidida por Jacques Delors, levantou quatro itens fundamentais para a educação: "aprender a conhecer, aprender a fazer, aprender a viver junto e aprender a ser..." .

Se considerarmos que as transformações são cada vez mais rápidas e a "renovação do saber e do saber fazer" tornam os saberes obsoletos algum tempo depois de adquiridos, se novas formas de acesso à informação (como as buscas hipertextuais), novos estilos de conhecimento e raciocínio (como a simulação), nova natureza do trabalho (colaborativo), novos ambientes (ciberespaço) se apresentam no fim deste século, prenunciando uma ecologia cognitiva diferente, urge que se faça uso da comunicação assistida por computador de forma interativa, integrada e intuitiva para que os alicerces indicados pela UNESCO sejam construídos.

A comunicação assistida pelo computador pode propiciar aos alunos ambientes multissensoriais e comunicacionais onde eles possam, orientados por seus professores, aprender a ser e aumentar sua auto-estima. Através do desenvolvimento de habilidades específicas dos alunos, respeitando-se estilos próprios de aprendizagem, a comunicação assistida pelo computador pode tornar esses jovens mais efetivos e produtivos, ao mesmo tempo que colaborativos e comunicativos.

Quando um aluno produz com o computador uma carta, um relatório, um desenho, uma composição musical ou uma produção multimidiática, ainda que em equipe, os programas e o computador foram ferramentas pura e simplesmente. Entretanto, se o professor orientou-os a produzirem colaborativamente, individual ou coletivamente, para expressarem e compartilharem suas idéias, emoções e sentimentos com seus companheiros e outros interlocutores, a tecnologia usada passou a ser meio de comunicação.

$\mathrm{O}$ acesso à Internet permite que alunos e professores das mais variadas regiões do mundo, com culturas diversas, de classes sociais diferentes e até de faixas etárias distintas se comuniquem e desenvolvam projetos colaborativos, construindo um novo conhecimento em conjunto, o que não seria possível com outro tipo de tecnologia. Novamente aqui a participação do professor é fundamental na comunicação entre todos os interlocutores. Se essa comunicação não for orientada, só existirá como troca de correspondência e enquanto houver novidade. Mas se professores e alunos trabalham em suas escolas colaborativamente em projetos que são compartilhados com outros alunos e professores de outras regiões, com outro tipo de cultura, uma comunicação multilateral e constante será fortalecida. $\mathrm{O}$ ciberespaço se apresenta como um ambiente em que as barreiras étnicas e sociais são praticamente inexistentes se respeitada a etiqueta da própria rede. Muitos dos preconceitos que se manifestam presencialmente são inexistentes na comunicação ciberespacial. Se os alunos forem levados a usar as suas funções cognitivas (memória, imaginação e percepção), sua experiência, troca de conhecimento, exercitando sua inteligência coletiva através da sinergia das suas capacidades e diversidades, o sistema educativo terá uma nova "qualidade, diversidade e rapidez no desenvolvimento dos conhecimentos" 10 . Dessa forma responde-se a um dos alicerces, que é o de aprender a viver junto e trabalhar em equipe localmente, respeitando as diversidades culturais, étnicas e sociais, tanto dos que estão próximos como daqueles de outras regiões do mun- 


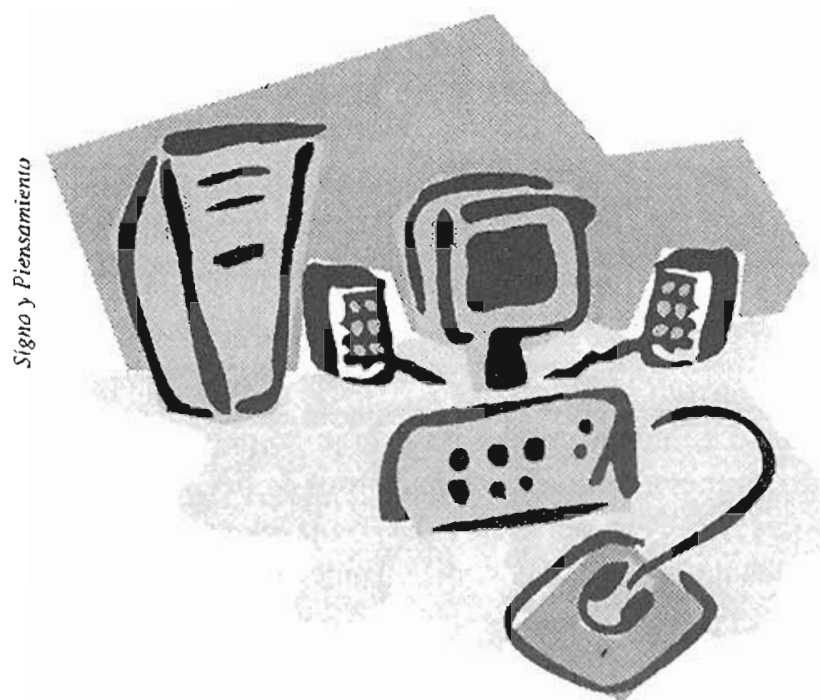

do. Cria-se então uma mentalidade voltada à "gestão inteligente e pacifica dos conflitos"".

Outro ponto fundamental é o desenvolvimento de habilidades e procedimentos que levem o indivíduo a aprender a conhecer não só na escola, em museus e bibliotecas, como informalmente, através das mídias e em ambientes fora da escola, como nos parques, por exemplo, desenvolvendo uma educação permanente que permita uma "construção contínua do ser humano, de seu saber e de suas aptidões, como rambém de sua faculdade de julgar e de agir"12.

Concluindo, educadores e pais devem se compromissar na orientação de seus alunos e filhos quanto ao uso não só da comunícação assistida pelo computador como no uso de quaisquer das mídias, eletrônicas ou não, informatizadas ou não, como mediadoras na consttução contúnua de si próprio como ser individual, coletivo, mas sabretudo como ser colaborativo, solidário e humano.
Resumo: O artigo trata de discutir a comunicaçāo escolar como prática pedagógica de interação entre professor e alunos. Destaca que as tecnologias de comunicação, em particular o computador, podem ser mediadoras, na construção conjunta do conhecimento. Elas favorecem a formação contínua de indivíduos, levando-os a aprender a ser, aprender a fazer, a conhecer e a trabalhar com os outros, de forma cooperativa, a fim de criar uma inteligência coletiva capaz de gerenciar conflitos e promover uma vida mais humana.

Palavras-chave: computador, mídia, aluno, professor, escola
Abstract: The article discusses school communication as an interactive teachıng praclice between the teacher and the students. It emphasizes the fact that communication technologies, particularly the computer, can be mediators in the joint construction of knowledge. They favor the individual's continual education, leading him or her to learn to be, to do, to know and to work with others in a cooperative manner, in order to create a collective intelligence capable of managıng conflict and promoting a more human life.

Key words: computer, media, student, teacher, school 